\title{
Katılımcı Kültür Tartışmaları Bağlamında YouTube: Eleştirel Bir Değerlendirme
}

Başvuru Tarihi: 30.04 .2021 Yayın Kabul Tarihi: 17.11 .2021 Yayınlanma Tarihi: 30.12 .2021

\author{
Selda Tunç Subaşi ${ }^{1}$ \\ Bağımsız Araştırmacı \\ seldatun@gmail.com \\ ORCID: 0000-0001-7009-4848
}

\section{ÖZET}

Bu çalışmada katılıma kültür kavramı, YouTube sosyal medya platformu örneğinde tartışmaya açılmaktadır. Video teknolojisinin gelişmesiyle profesyonel ya da amatör içerikler, YouTube'da dolaşıma sokulmakta eğlence, müzik, eğitim, aktivizm ve siyasete uzanan konularda tartışma ortamları oluşmaktadır. İzleyicinin aynı zamanda kullanıcı olduğu sosyal ağlardan biri olan YouTube, etkileşimi yapılandıran arayüz teknolojileriyle katılımcı kültürel pratikleri toplumsal bir dönüşme uğratmaktadır. Bu dönüşüm, gündelik hayat kültürü içinde oldukça "sıradan" bir deneyim halini alan video izleme ritüellerinin niteliği üzerine düşünmeyi gerekli kılmaktadır. YouTube, bir sosyal medya platformu olarak yeni hiyerarşi ve sınırlarla oluşturduğu katılıma kültür ekosistemi içinde görüntülenme oranına göre "parlayan videoları" öne çıkararak izleyicinin seçimlerini etkilemektedir. Tabandan gelen veri akış trafiğinin kontrolü şirket politikalarıyla yapılanmakta olduğundan platform kullanıcısı videolarını diğer videolarla rekabet ve yarışma ortamında yeniden üretmektedir. Giderek e-ticaret modelini benimseyen bu sosyal medya platformunda, video içerikleri muazzam bir çeşitliliğe sahip gibi görünse de video önerileri döngüsü bu çeşitliliği daraltmaktadır. Gerçekleştirilen bu betimsel çalışmada, arayüzdeki "aktif katılımcının", platform tarafından tüketici davranışına dayalı veri akışı sağlayan bir kitle olarak görüldüğü sonucuna ulaşılmıştır.

Anahtar Kelimeler: YouTube, katılımcı kültür, arayüz, kullanıcı, video.

1 Doktor 


\title{
YouTube in the Context of Participatory Culture Debates: A Critical Evaluation
}

\author{
Selda Tunç Subaşi \\ Independent Researcher \\ seldatun@gmail.com \\ ORCID: 0000-0001-7009-4848
}

Application Date: 30.04 .2021

Accepted Date: 17.11.2021

Publishing Date: 30.12 .2021

\begin{abstract}
The aim of this study is to develop a better understanding of "participatory culture" through YouTube platform. The technological progress of video leads to professional and ameteur contents are circulated at YouTube interface, the discussion platforms have extending to several topics such as the entertainment, music, education, activism, politics. YouTube web site is one of social networks where the audience is also user, the interactive interface technology determines social transformation in participatory culture. It should be considered on video watching experience, which is habitually being in everyday life-culture. This study indicates that YouTube platform is gradually by adopting e-commerce model, and it directs cultural chocies of users and generates "ranking culture". YouTube web site influences audience's content chocies according to ratings and gives privilege some videos in participatory culture ecosystem that has new borders and hierarchical positions. The user reproduces new contents and compete with the other videos while YouTube policies control over meta datas coming from bottom-up (consumer based) knowledges. In this platform, the video contents look like offering a having diversity materials but the site has not them. In this descriptive study based on a literature review show that "active participants" is seen more like a mass that is based on data stream connect to consumer behaviour.
\end{abstract}

Keywords: YouTube, participatory culture, interface, user, video.

2 Ph.D. 


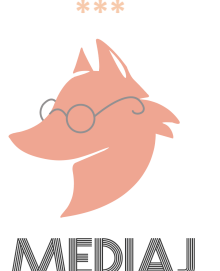

\section{Giriş}

Kullanıcıların diğer kullanıcılar tarafından üretilen videoları ücretsiz paylaşıp görüntüleyebilecekleri bir sosyal medya platformu olan YouTube, 2005 yılında üç PayPal çalışanı Chad Hurley, Steve Chen ve Jawed Karim tarafından kurulmuştur (Chau, 2010, s. 66). Wikipedia, Myspace ve Facebook gibi kullanıcı tarafından oluşturulan içeriğe dayalı bir dizi web sitesinin öneminin giderek daha belirgin hale geldiği bir dönemeçte Google şirketi, 2006 yılında YouTube'u 1,65 milyar ABD doları karşılığında satın almıştır (Arthurs vd., 2018, s. 3). Ticari yolculuğuna Google şirketi ile başlayan YouTube, aynı zamanda video paylaşımının teknik bariyerlerini yıkan servis sağlayıcılardan biri olarak ortaya çıkmıştır. Bu sosyal medya platformu, kullanıııların yüksek düzeyde teknik bilgiye gereksinim duymadan akışlı videolar yükleyebilecekleri ve görüntüleyebilecekleri basit, entegre bir arayüz sağlamıştır. Platform, kullanıcıların yüklediği video sayısına sınır koymazken diğer kullanıcılarla bağlantı kurma fırsatı vermekte ve videoların diğer web sitelerine entegre edilmelerini kolaylaştıran URL ve HTML kodları sağlamaktadır. "Broadcast Yourself" (Kendini Yayınla) sloganıyla dijital video arşivi ve kullanıcı liderliğini işaret eden YouTube, zamanla kişilerin kendini ifade etme aracı haline gelmiştir (Burgess \& Green, 2009, s. 1-3). Bu sosyal medya platformunun en temel özelliklerinin ilki, bir medya şirketi olarak içerikleri toplarken içerik üretmemesidir ${ }^{3}$. Ikincisi, kullanıcı katkılı içerik (User Generated Content) üretimini destekleyerek yeni izleyici ve kullanıcılara yönelik katılım biçimlerinden gelir akışı elde etmesidir. Üçüncüsü, platform bünyesinde kullanıcı katkılı içeriklerle profesyonel içerikleri (Professionally Generated Content) yan yana getirmesidir (Burgess \& Green, 2009, s. 4-5). Bunlarla birlikte platform, görsel işitsel bir koleksiyon üretmek için dosyaları yükleme, arama ve bulmaya dönük teknolojik bir girişim başlatmıştır. Bu teknoloji, Web 2.0'la birlikte veri tabanına öğe ekleme ve kullanıcı tarafından oluşturulan meta bilgiler yoluyla bilgi yönetimini geliştirmeye dönük bir arayüzü (Application Programming Interface [API]) devreye sokmasıyla görünür hale gelmiştir (Kessler \& Schäfer, 2009, s. 275-279).

Yukarıda belirtilen teknolojik özelliklerin yanı sıra YouTube videoları, kendi veri tabanı harici sitelerde de logosunu koruyarak kullanıcılara erişimini genişletmiştir (Lange, 2008, s. 89). Örneğin, 2007 yllında platform, BBC (British Broadcasting Corporation) web sitesini geride bırakarak Ingiltere'de en popüler eğlence platformu olmuştur. Bu popülerleşmede platformun genç kitlelere ulaşma potansiyeli özellikle dikkat çekicidir. Genç toplulukların müzik videolarına olan ilgisi bu yayılımı genişletmiştir (Manovich, 2008, s. 35). Mark Andrejevic (2009) YouTube'un ilk yıllarında popüler videoların birçoğunu müzik videolarının oluşturduğunu dile getirmektedir. Google'ın YouTube'u henüz satın almadığı bir dönem olan Aralık 2005 yılında, "Lazy Sunday" adlı bir video klip çevrimiçi olarak ilk on gününde 1,2 milyon kez görüntülenmiştir (Burgess \& Green, 2009, s. 3). Müzik videolarının tanınırlığını arttırmasının yanında, küresel bir büyümenin de eşlik ettiği bir medya şirketi olan YouTube, şimdilerde 1,68 milyar kullanıcıya sahip oldukça popüler bir platformdur. 2019 yılı verileriyle İnternet kullanıcıları arasında yayılan video içeriklerine bakıldığında YouTube'a her dakika 500 saatten fazla video yüklendiği görülmektedir. Eğlence, müzik, ünlüler (YouTuber/Vlogger) olarak kategorize edilen videolar, YouTube'da en yüksek görüntülenme payına sahip olan video kategorilerini oluşturmaktadır (Clement, 2020). Bu sosyal

${ }^{3}$ Çalışmada taranan literatüre giremese de YouTube, bugün geldiği noktada kendi içeriklerini üretmektedir. Ayrıntılı bilgi için bkz.

https://www.youtube.com/results?search_query=youtube+originals (Erişim Tarihi: 13 Aralık 2020). 


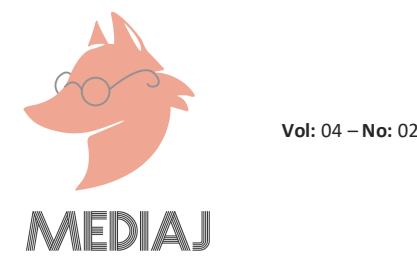

medya platformu, 2020'de benzer web siteleri içinde dünyada Google'dan sonra ikinci sırada yer almaktadır (Hootsuite, 2020). Bununla birlikte platformda reklamsız içerikler için ücretli Premium üyelikler mevcut olup popüler kablolu kanallar ve anakım yayıncılık hizmetlerinin olduğu yeni bir hizmet de devreye girmiştir (YouTube, 2020).

Araştırmacılar tarafından YouTube, öncelikle bir platform, çevrimiçi hareketli bir görüntü arşivi, bir kütüphane ve "veri imge kaynağı" olarak yorumlanmıştır (Iversen, 2009, s. 355; Kavoori, 2015 , s. 2; Rick, 2009, s. 268; Schröter, 2009, s. 330). Bu tanımlamaların dışında platformun kullanıcılarla paylaşılan çevrimiçi bir dijital kültür deneyimi yarattığına dönük düşünceler geliştirilmiştir (Burgess \& Green, 2009; Jenkins, 2006; Kavoori, 2015; Strangelove, 2010). YouTube öncesi video deneyimi amatör ev videolarına (home videos) uzanmakta, 8 ve 16 mm'lik analog film kameralarıyla aile üyeleri, yakın arkadaşlar, düğünler, doğum günleri ve tatiller gibi bir dizi etkinlik videoya kaydedilmektedir (Strangelove, 2010, s. 26). Michael Strangelove'a (2010) göre, sınırlı bir çevreyle oluşturulan ve kaydedilen videolar bir arşiv olmanın ötesinde "sıradan insanların" anlam dünyalarında bir deneyime dönüşmektedir. Bu deneyim, Jean Burgess ve Joshua Green'e (2009) göre, popüler kültürün YouTube ortamında dağıtımıyla "yukarıdan aşağı" şirket politikaları ve "aşağıdan yukarı" taban hareketi ile kültüre içkin bir yaratıcılık (Vernacular Creativity) temelinde hareket etmektedir. Bu çifte akışta, katılımcı olanın kültürler olduğunu teknolojiler olmadığını belirten Jenkins (2016) YouTube gibi platformların sosyal teması sürdürmek ve kültürel üretimleri paylaşmak için yalnızca bir araç olduğunu belirtmektedir. Fakat, YouTube'un katılımcı kültüre şekil verirken sosyal ağdaki diğer platformlarla rekabet halinde ve güç mücadelesi içinde olduğu da eklenebilir. Platformun kullanıcılara sınır koymayan teknolojik mimarisi katııım kültüründeki "demokratik katılım" nosyonunu güçlendirirken, ekonomik potansiyelinin gelişmesi için kullanıcılar (aşağıdan yukarıya) ve kurumsal (yukarıdan aşağıya) uygulamalar sürekli karşı karşıya gelmektedir (Wasko \& Erickson, 2009, s. 372). Bu çalışmada, YouTube izlemenin ve içerik üretmenin "sıradan" hale geldiği bir gündelik deneyimde, katılımcı kültürel pratiklerin YouTube tarafından nasıl şekillendirildiği ortaya çıkarılmaya çalışılacaktır. Çalışma açısından YouTube sosyal medya platformunun yapısal işleyişinin açığa çıkarılması, katıımcı kültürel pratiklerin sorgulanmasında üzerinde durulacak önemli bir konuyu oluşturmaktadır.

YouTube'un kültürel, sosyal ve ekonomik değerlerini üreten sosyal ağındaki katılımcılardır (Burgess \& Green, 2009a, s. 98). “Digital 2020" raporuna göre YouTube, Türkiye'de en çok ziyaret edilen sosyal medya platformlarından biri olarak ikinci sırada yer almaktadır (Hootsuite, 2020). Öte yandan, platform kullanıcılarını, yaş ve cinsiyet gibi birimlerle sınıflandırmak kolay görünse de aynı şeyi YouTube videolarının sınıflandırılması için söylemek pek mümkün değildir. Platform, eski ve yeni televizyon şovlarından filmlere, oyun ya da müzik videolarına uzanan profesyonel ve amatör video içeriklerinin bir arada bulunduğu bir çeşitliliğe sahiptir (Kavoori, 2015, s. 1; Fagerjort, 2010, s.187). Platforma katkı sunan kullanıcılar da en az içerikler kadar çeşitlidir. Bunlar medya holdingleri, televizyon istasyonları, sanatçılar, aktivistler, kültür kurumları, hayran toplulukları, amatör medya üreticileri, politikacılar, haber kuruluşları vb. birçok kesimden kurum, kuruluş ve topluluk YouTube platformunu kullanmaktadır (Burgess \& Green, 2009a, s. 103).

Büyüyen kullanıcı çeşitliliği, YouTube kültürünü anlamaya dönük motivasyonların araştırılması gerekliliğini de beraberinde getirmektedir. Türkçe literatürde platform özelinde artan bir yazın 


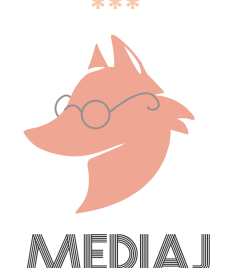

göze çarpmakta ve katılımcı kültürü YouTube ve kullanıcı ilişkisi üzerinden ele alan incelemeler çoğalmaktadır. Bu çalışmalardan bazıları şu şekilde sıralanabilir: YouTube'u, alternatif bir iletişim aracı (Aydoğdu \& İlhan, 2020), içerik üretiminin ekonomi politiği (Erdoğan, 2020), çocuk ve genç izleyicilere etkisi (Atalay, 2019; Güzel vd., 2020), eğitim ve öğretim ortamı (Ata \& Atik, 2016; Yunus \& Kaleci, 2018), gazetecilik pratikleri (Bulut, 2020), geleneksel unsurlar ve kimlik (Gülüm, 2019; Gülüm, 2020), kullanım motivasyonları (Arklan \& Kartal, 2018; Biçer \& Şener, 2020; Kuyucu, 2019; Pazarbaşı \& Toğlukdemir, 2019; illhan \& Aydoğdu, 2019), gündelik yaşam kültürü (Gelebek, 2020), sosyal medya ve dolaşım ağı (Ateşalp \& Başlar, 2015; Çetin \& Ayhan, 2020), kültürlerarası iletişim (Işıkman, 2016), güzellik kanalları (Genç, 2019); şöhret kültürü (Altun, 2019); toplumsal cinsiyet (Akbaş \& Atalay, 2020), yeni medya ekolojisi (Zinderen, 2020), müzik videoları (Çelik, 2018) ve YouTuber'lık (Ergen, 2019; Güler, 2018; illhan \& Aydoğdu, 2018; Özüz, 2018) gibi konular bağlamında sorgulayan çeşitli çalışmalar yapılmıştır. YouTube sosyal medya platformu, görülmektedir ki video akışını sağlayan bir arşiv oluşturmakta, aynı zamanda kullanıcılardan gelen veri akışının kullanıcılar arasında etkileşimlere yol açtığı bir kültürel alan yaratmaktadır. Peki, bu kültürel alan nasıl bir katııımcı kültür yaratmıştır? Platformda, hangi kurallarla katılımcı kültürün yeniden şekillendirildiğinden söz edebilir? Bu sorulardan hareketle çalışmanın temel bulgusu, giderek e-ticaret modelini benimsemeye başladığını söyleyebileceğimiz YouTube platformunun katılım kültürünü gittikçe hiyerarşik bir "sıralama kültürü"ne (ranking cultures) $)^{4}$ doğru çektiğinin ortaya çıkmasıdır. Dolayısıyla bu çalışmanın temel amacı, platformdaki video kültürünü aktif hale getiren kullanıcı pratikleri ile platformun şirket çıkarları arasında yaşanan gerilimin hangi unsurlardan beslendiğini ortaya çıkarmaktır. Çalışmanın varsayımı ise YouTube'un hem amatör içerik üreticileri hem de ticari medya yapımlarını İnternet ekolojisinde bir araya getirerek bir köprü kurarken, yeni sınırlar ve hiyerarşiler yarattığının savunulmasıdır. Çalışmada, YouTube'daki kullanıcıların nasıl bir kültürel deneyim içinden geçtikleri ve platformun toplumsal ilişkilerin yönlendirilmesindeki rolüne odaklanan betimsel bir değerlendirme türü olan "bütünleştirici değerlendirme"den yararlanılmıştır. Bu teknikte bir konuyla ilgili mevcut bilgi durumu sunularak özetlenmekte, konu hakkında uzlaşmalar ve uzlaşmazlıkların altı çizilmektedir (Neuman, 2010, s.166). Bütünleştirici değerlendirme ile ele alınan literatür, çalışmanın araştırma soruları ve varsayımları ışığında eleştirel bir değerlendirmeyle ele alınmıştır. Böylelikle katılımcı kültür kavramının YouTube özelinde nasıl bir toplumsal dönüşüme uğradığı ve nasıl bir bilgi birikiminin üzerinde yeni anlamlar yüklendiği tartışmaya açılmış olmaktadır.

\section{KATILIMCI KÜLTÜR ORTAMLARINDA KULLANICI DENEYIMI}

1980'li yıllarda kültürel çalışmalar alanında bir kırılma noktasına denk düşen kültürel dönemeç (cultural turn) medya kurumlarının gündelik yaşam üzerindeki etkilerine odaklanmaya başlamıştır. İzleyicilerin medya metinlerini alımlamaları bu yıllarda ilk etapta romanlar, dergiler, televizyon programları ve diziler aracılığıyla gerçekleşmiştir. Medya dolayımıyla bireylerin hem ekonomik hem de anlam dünyalarının nasıl şekillendiği sorusu kültürel çalışmaların ilgisini izleyicilere yöneltmiştir. Bugün dijital çağda bu soru geçerliliğini korumakla birlikte platformların mikro bağlamlarda kendine özgü alanlar yarattığı ortaya çıkmaktadır. Bu alanlar, YouTube'da

\footnotetext{
4 "Sıralama kültürü" kavramı yazarlara atıfla kullanılmıştır: Rieder, B., Matamoros-Fernandez, A., \& Coromina, O. (2018). From ranking algorithms to 'ranking cultures' investigating the modulation of visibility in Youtube search results. Convergence, 24(1), 50-68. doi:10.1177/1354856517736982.
} 


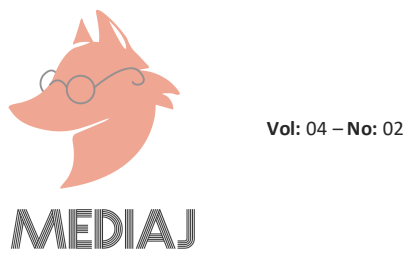

eğitimden aktivizme, siyasete ya da hobilere uzanan video türlerinin çeşitliliğinde açığa çıkmaktadır.

İngiliz Kültürel Çalışmalar Ekolü’nün katılımcı kültüre yönelik erken tarihteki izleyici çalışmaları len Ang'in (1985) Watching Dallas ve Janice Radway'in (1984) Reading the Romance adlı eserleridir. Savaş sonrası İngiltere'sinde işçi sınıfı gençlik kültürünün hâkim sınıfa karşı gerçekleştirdiği sembolik direniş biçimleri üzerine yapılan altkültür çalışmaları ise diğer örnekleri oluşturmaktadır. Bu gençlik grupları, egemen kültüre karşı kendi kültürel değer ve sembollerinde ısrar etmişlerdir (Hall \& Jefferson, 1993, s. 82; Hebdige, 2004, s. 15). Dijital kültürde ise katılımcı kültür pratiklerini direniş ya da muhalif bir kültür olarak tanımlamak ve böylesi sert bir ayrım kategorisi ortaya koymak kolay gözükmemektedir. Örneğin, İngiliz kültür teorisyenlerinin punk ya da teddy boys gibi gençlik altkültür çalışmaları, muhalif kültür ya da direniş kültürü olarak karşısına ana akım kültürü yerleştirmektedir. Oysaki dijital kültürün varlığıyla biçimlenen katılımcı kültüre ait topluluklar yıkıcı, eleştirel ya da müzakereci gibi adlandırmalarla medya endüstrisinin birer parçası haline gelmekte, hâkim kültüre ancak bu yeni konumlarından yanıt üretmektedirler (Jenkins vd., 2016, s. 25-31). Jenkins (2016) çevrimiçi ortamlarda altkültür gruplarının kendilerini karşı kültürde konumlandırabilecekleri ve ana akım kültürden ayrı tutabilecekleri bir sınırın olmadığını vurgulamaktadır. Örneğin, okulda başarısız olan bir öğrencinin çevrimiçi oyun dünyasında bir lider olabileceği ya da aile üyeleri tarafından ciddiye alınmayan bir kişinin sanal mekânlarda bir kurgu yazarı olarak şöhret kazanabileceğinin altı çizilmektedir. Görülmektedir ki "sıradan" kullanıcılar, YouTube gibi platformlar aracılığıyla dolayımlanan kültür içinde anlam oluşturan "aktif bir fail" konumuna yükselmekte, gerçekliğin kendine özgü versiyonlarını (bricolage) yaratmaktadırlar (Deuze, 2006, s.66).

Modern endüstriyel dönemde boş zaman ve çalışma zamanı arasındaki bölünmüşlüğün ideolojik yanılsaması, kültür endüstrilerinin boş zamana sızan Kendin Yap (Do It Yourself) kültürüne ait yaşam tarzlarında ortaya çıkmaktadır (Adorno, 2005, s. 187). Bernard Stiegler (2009) küresel düzeyde yaşanan dijitalleşmeyle boş zaman mefhumuna kültür endüstrilerinden ziyade artık kültürel teknolojilerin hâkim olduğunu izleyicinin değişen rolleriyle kolektif düzeydeki üreticitüketici döngüsünde bir kopma yaşandığını belirtmektedir. Bu döngüyü İnternet/ağ ortamını kullanan platformlar aracılığıyla da görmek mümkündür. YouTube henüz gençlerin ilgi alanlarına dayalı bir web arşiv koleksiyonuyken bu koleksiyondaki videolara ilişkin yapılması gereken işler (şikayetler, sınıflandırmalar, istekler vb.) gönüllü, akran ve arkadaş topluluklarının kolektif iş birliğine dayanmaktaydı. Bu sosyal medya platformu, Google tarafından satın alındıktan sonra şirketler tarafından kontrol edilen ve şirketlerin içerik üreticileriyle izleyiciler arasında aracı rolü üstlendiği bir sisteme doğru geçiş yapmıştır (van Dijck, 2009, s. 52). Bu sistemde, popüler kültürle karma bir etkileşim modeli içinde olan kullanıcılar, kısmen üretici kısmense tüketici konumundadırlar. Bu yeni modeldeki çatışma unsurları, yukarıdan aşağı doğru akan bir kontrol ve aşağıdan yukarı doğru yapılanan üretim sistemleri arasında yaşanmaktadır (Burgess \& Green, 2009 , s. 14). Örneğin, ağ teknolojilerinde, izleyicilerin "aktif içerik üreticisi" olarak medya çıktılarının dolaşımında rol üstlenmeleriyle birlikte halihazırda kullanıcı olan izleyiciler, medya şirketleriyle ilişkilerini müzakere etme şansı yakalamış ve şirket kurallarına karşı bir baskı unsuru olabileceklerini fark etmişlerdir (van Dijck, 2009, s. 43). Kullanıcıların medya teknolojilerine eklemlenmeleriyle kurumsal olduğu kadar söyleme gömülü olan bu teknolojiler, toplumsal katmandaki diğer söylemlerle etkileşim, rekabet ve mücadele içine girmişlerdir (Carpentier, 


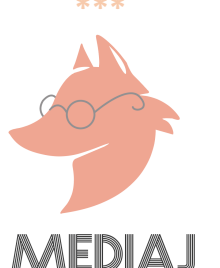

2011, s. 146-271).

Katılımcı kültür kavramını popülerleştiren Jenkins, bu kavramla izleyici, tüketici ve hayran topluluklarının ürettiği içeriklerle yaratılan bir kültüre katılmayı işaret etmektedir (Fuchs, 2020, s. 102). Kavram, sermaye yoğun endüstrilerin tekelinde olan teknolojilerin aksine, "sıradan" vatandaşların medya teknolojilerine katılımını teşvik etmektedir (van Dijck, 2009, s. 43). Yeni medya ortamlarında Jenkins (2018) "medya yapımcısıyla medya tüketicisini, taban medyası ile kurumsal medyayı kesiştirerek" katılım kültürünü şekillendiren medya yakınsamasının (convergence) "aşağıdan yukarı" doğru hareket eden bir içerik akışıyla gerçekleştiğini belirtmektedir. Tabanda üretilirken haber ve eğlence formlarında karşılık bulan yurttaş haberleri ya da görsel işitsel hicve dayalı siyasi parodiler, cep telefonu aracılığıyla yayılırken bu bilgilerin medya yakınsaması yoluyla farklılaştığı görülmektedir (Jenkins, 2018, s. 36-39). Dijital kültüre katılımın yakınsama kültürü içinden çeşitlenmesiyle amatör içerik üreticilerinin yaratıları, medya endüstrilerinde daha fazla görünürlük kazanmaya başlamıştır (Jenkins vd., 2016, s. 18). Genç hayran grupları genellikle eğlence kültüründen devşirdikleri içeriklerin yeniden düzenlenmesine (remix) odaklanmışlardır. Fakat yalnızca hayran toplulukları değil birçok kurum, kuruluş ve işletme katıım retoriğini benimsemeye başlarken Jenkins (2016) medyaya her sektörden akan katılım biçimlerinin eşit derecede anlamlı ve güçlendirici olmadığının altını çizmektedir. Bu görüşün temelinde, medya şirketlerinin kullanıcının kolektif içerik üretiminden faydalanması ve amatör üreticinin kendi içerikleri üzerinde sınırlı bir güce sahip olması gibi bir endişe yer almaktadır. Ayrıca kullanııının özgürce ürettiği içeriklerden söz etmekten ziyade şirketlerin kullanııının ürettiklerine sınırlılıklar getirmesi söz konusudur (Jenkins \& Carpentier, 2013, s. 273).

Katılımcı kültür nosyonuna Jenkins'le benzer bir noktadan yaklaşan Danah Boyd (2016) genç grupların katılımcı kültürle kişisel, eğitimsel, politik ve sosyal nedenlerle etkileşime eskisinden çok daha fazla katılmalarını olumlasa da yeni medya şirketlerinin gençlerin içerik üretimlerini ticari alandaki çıkar çatışmalarına yönlendirdiğini belirtmektedir. Bu çatışma, şirketlerin "aktif içerik üreticisi" söyleminde oldukça görünürdür. YouTube'daki kullanıcı katılımını beğenme/beğenmeme (likes/dislikes), yorum (comments) ve görüntülenme sayısına doğru kanalize etmek özellikle pazarlamaya ilişkin bilgi akışını teşvik etmektedir (Khan, 2017, s. 245). Oysaki katılım sadece "aktif üretici" anlamına gelmemekte, aynı zamanda paylaşılan bir pratiğin ve kültürün bir parçası olmakla ilgilidir (Jenkins vd., 2016, ss. 19-21). Katılımcı kültür, tek yönlü pozitif anlamlarla dolu topluluk temelli bir kavramdan ziyade, siyasal ve ekonomik boyutlarının işin içinde olduğu çok katmanlı bir kompozisyon oluşturmalıdır.

\section{YouTube Arayüzünde Veri Akışı}

YouTube kanalı, bir kişi bir hesap oluşturmak için kaydolduğunda kişiye verilen özelleştirilmiş bir hesaptır. Bu hesapla, platformda gezinme ya da içerik (video) yüklemesi yapılabilir. Kanala abonelikler ise kanalı izleyen kişi sayısını göstermektedir. Bir hesaba sahip olmak, insanların izledikleri herhangi bir videoyu beğenmesine, yorum yapmasına ve paylaşmasına olanak tanımaktadır (Zanatta, 2017, s. 10). YouTube'da, abone olunan herhangi bir kanalda yeni bir video yayınlandığında güncellemeleri almak için özelleştirilmiş bir profil ve abonelik listelerinden yararlanılmaktadır (Chau, 2010, s. 72). Bir kanalın abonesi olmak aynı zamanda yeni videolar yayınlandığında uyarılacağınız anlamına da gelmektedir. Kullanıcı topluluğu içindeki bu döngüsel 


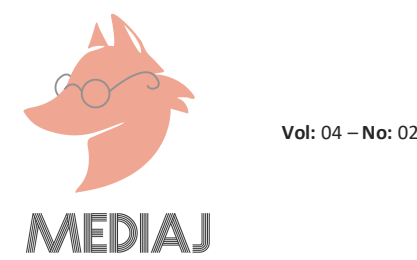

pratiklerin aksamadan işlemesi için YouTube sayfasının yapısı oldukça önemlidir. Bu sayfa yapısında üreticinin faaliyetleri bir havuzda toplanarak videolar arasında hızlı bağlantılar kurulabilmektedir (Peters \& Seier, 2009, s. 194). YouTube arayüzü bu bağlantıları veri tabanındaki video aramalarını içeren ortak bir arama çubuğu yoluyla kurmaktadır. Platform, bilgi yönetim sistemini videoların anahtar kelimelere göre bulunmasını sağlayan ve otomatik okunabilen etiketlere dayandırmakta bu sayede arama süreçleri de otomatikleşmektedir (Kessler \& Schafer, 2009, s. 281).

YouTube'un video depolama mantığının temelinde başlıklar, etiketler, anahtar kelimeler, hiper bağlantılar (hyperlink), kısa açıklamalar, görüntülenme sayıları ve özyineli bağlantılar (recursive links) gibi istatistiki hesaplamaya yardımcı olan meta bilgiler bulunmaktadır. Videolardaki hareketli görüntüler anlamsal içerik taşımadığından bilgi yönetimi özellikle bu meta verilere dayanmaktadır (Kessler \& Schafer, 2009, s. 279). Kullanıcılar bir video yükleyecekleri zaman onlardan YouTube arayüzüne yüklenecek videoya uygun bir kategori seçmeleri istenmektedir. Oldukça geniş olan bu kategoriler verimli bir aramayı oluşturamadığında, kullanııılar içeriklerinin daha spesifik kategorilerini formüle etmek için platforma ek etiketler ekleyebilmektedir (Kessler \& Schafer, 2009, s. 282). Oluşturulan bu video kodları, YouTube'un arama isteklerine verdiği yanıtları da etkilemektedir. Bu sebeple YouTube veri tabanında gezinmek aynı zamanda verimli bilgi yönetimi için gerekli meta bilgileri sağlayan çok sayıdaki diğer kullanıcıların faaliyetleriyle de içsel olarak ilgili olmaktadır (Kessler \& Schafer, 2009, s. 281). Örneğin, arama çubuğuna anahtar kelimeleri yazarak seçim yaptığınız bir videoya yöneldiğinizde bu videodaki beğeniler eğer beğenmeme sayısından daha fazla sayıda ise bu video yalnızca birkaç yüz ziyaretçinin bulunduğu bir içerikten daha çok dikkat çekebilmektedir (Duncum, 2011, s. 30). YouTube'da kullanıcıların eylemleriyle belirlediği sıralamada video başarısı, çok sayıda abone kazanmak ve her video için milyonlarca görüntülenme anlamına gelmektedir (Burgess \& Green, 2009, s. 73).

YouTube kullanıılarının, kodlanmış mekanizmalar aracılığıyla belirli videolara yönlendirildikleri görülmektedir. Bu yönlendirme işleminde YouTube, en çok izlenen (most viewed), en beğenilen (most popular) ve en çok yorumlanan (most discussed) videoları sıralamaktadır (van Dijck, 2009, s. 45). Ayrıca, platform izlenmekte olan videonun yanına yapılan aramalarla ilgili bir dizi videoyu (related videos) da sıralamaktadır (Lange, 2007, s. 376). Platform ana sayfasında, sponsorlu videolar (promoted videos) ve öne çıkan videolar (featured videos) yer almakta, bu içerikler istatistiki veriler doğrultusunda kullanıcıya sunulan seçenekleri oluşturmaktadır. Sıralanan videolar, yapılan seçimler doğrultusunda tematik olarak organize edilmiş kapsayıcı bir anlatı sunarken diğer yandan platformun sıralama kriterlerine göre oluşan baskın bir formatı işaret etmekte ve kültürel ürünlerle izleyicinin karşılaşmasında izleyiciye yapılandırılmış bir çeşitlilik sunmaktadır (Kessler \& Schafer, 2009, s. 280). Arayüzün sağladığı içerik çeşitliliği, veri tabanın her izlemeyi hesaba katması ve en çok görüntülenen videoların ana sayfada izleyiciye tanıtılmasından oluşmaktadır. Ziyaretçiler ve içerik oluşturucular izlenen video sayılarındaki artışı her videonun yanında belirgin bir şekilde yer alan görüntülenme sayılarından öğrenebilmektedir (Chau, 2010, s. 71).

Görüntüleme oranı, belirli bir anahtar kelimeyle eşleşen videoların sırası için bir kriter olduğundan videoları izleyen kullanıcılar da platforma örtük olarak meta bilgi sağlamaktadır. Bu meta bilgiler, başlık koyma, ek bilgi verme, etiketleme, beğenme, yorum ve şikâyet etme gibi 


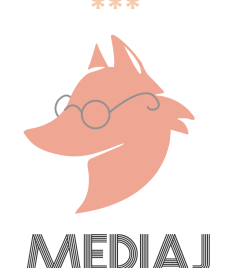

pratiklerle gerçekleşmektedir. Örneğin, içeriğe uymayan etiketleme yapmak kasıtlı bir yanlış bilgilendirmeyle video dosyasını görüntülemeye ikna etme çabasını ifade etmektedir. Bu tür videolar, görüntülenme sayısını artırmak için etiketlerin, başlığın ve açıklamanın yanlış kullanılmasını ifade etmekte, içerik yükleyiciler tarafından kasten yapılan ve sık gerçekleştirilen yönlendirmelerden birini oluşturmaktadır (Kessler \& Schafer, 2009, s. 281-284).

Kullanııların profilleri ve bu sosyal medya platformundaki gezinme davranışları da bir diğer meta veri sağlama kaynağıdır (van Dijck, 2009, s. 47). Bir videodaki her tıklama ve yapılan rastgele bir seçim, tesadüfi bile olsa veritabanı beslemektedir. YouTube sosyal medya platformuyla her etkileşim sistemde izlenmekte ve popülerliğin bir göstergesi olarak okunabilen kayıtlı istatistikler haline gelmektedir. Bu örtük katılım eylemleri, yazılım tasarımına dayanmakta ve arayüze yerleştirilmektedir (Andrejevic, 2009, s. 407; Kessler \& Schafer, 2009, s. 285). Çevrimiçi platformların kurucu unsurları olan bu algoritmalar, günlük sosyalliği videolar aracılığıyla şekillendirirken YouTube platformu bir içerik sağlayıcı olarak videoların sıralanması ve derecelendirilmesini algoritmalarla desteklemektedir (Rieder vd., 2018; van Dijck, 2009, s. 45). YouTube algoritması, kullanıcılara hangi içeriklere erişmeleri ve hangi içerikleri görüntülemeleri gerektiğini öneren bir sisteme sahiptir. YouTube öneri listesinin belirlenmesinde rol oynayan sıralamaya dayalı bu sisteme ise öneri sistemi (recommendation system) adı verilmektedir. Bu sistem, YouTube algoritması iş birliğine dayalı filtreleme analizi (collaborative filtering analysis) ile gerçekleştirilen bir hesaplama ilkesine dayanmaktadır (Arthurs vd., 2018, s. 10). Bu algoritmik sistemin nasıl çalıştı̆̆ı müzik tüketimi üzerinden bir örnekle gösterilebilir. Massimo Airoldi, Davide Beraldo ve Alessandro Gandini'nin (2016) "Follow the algorithm: An exploratory investigation of music on YouTube" çalışmasında, YouTube arayüzünün bir kopyasından elde ettikleri 22.000 'den fazla müzik videosunu kümeleyerek sosyal ağ analizi yoluyla bu videoları incelemişlerdir. Yapılan çalışmanın sonucunda, müzik videolarının sınıflandırılmasında tür ve kronolojik ilişkilendirmelerden daha anlamlı olan şeyin anlık ve moda göre değişen kriterlerin gruplandırılması olduğu görülmüştür. Platform, koşu ya da akşam yemeği gibi günlük rutinlerden, ruh hali gibi anlık duruma göre değişen videolarla müzik tüketiminde Spotify gibi müzik platformlarına özgü olan bir tüketim özelliğinden yararlanmıştır. İncelenen YouTube videolarının gruplandırılmasında sosyal pratikler kadar önemli olan bir diğer özelliğin algoritmik hesaplar olduğu ortaya çıkmıştır (Arthurs vd., 2018, s. 10).

Bernhard Rieder vd., (2018) yaptığı araştırmada ise YouTube videolarındaki seçime dayalı otomatik sıralamada, video popülerlik ölçütlerinin abone olunan kanalların görüntülenme sayılarıyla bağlantılı olduğu ortaya çıkmıştır. Popüler video sıralamalarının içeriğin dağılım süreçlerinde önemli bir rol üstlendiği görülmektedir. Araştırmacılar, YouTube arama algoritmasının dikkat döngülerini (attention cycles) alıp güçlendirdiğini ve YouTube'da hiyerarşik listeleri belirleyerek "sıralama kültürü" (ranking cultures) ürettiğini ifade etmektedirler (Arthurs vd., 2018, s. 12). "Sıralama kültürü", ticari olan ve olmayan videolar arasında bir ayrım yapmadığından içerikler arasında bir ayrım yapmak giderek güçleşmektedir. Popüler videolar arasında rating sistemiyle bir rekabet yaratılmakta ve YouTube ziyaretçisi geniş bir arşive rağmen en popüler videoları görmeye başlamaktadır (Iversen, 2009, s. 352). Algoritmalar kullanıcının içerik üretimini, medya ekosistemindeki yerini tayin etmekte ve dikkat döngüleri yaratmaktadır. Bu ekosistemde kullanıcılar, videoları beğenme (like) ve beğenmeme (dislike) gibi eylemleriyle yeni medya ortamlarında izler bırakmaktadır (Khan, 2017, s. 236). Bu eylemleri 


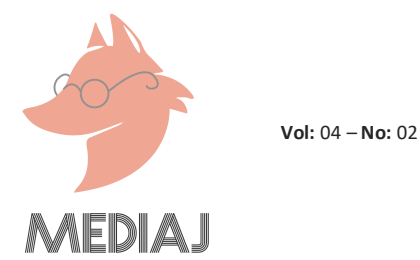

gerçekleştirmeyip sadece video izleyen ya da yorum yapmadan video paylaşan kullanıcılar da medya ekosisteminde yer almakta ve potansiyel katılımcıları oluşturmaktadır (Burgess \& Green, 2009, s. 57). Gerçek şu ki bir kişi YouTube platformunda bir düğmeye bastığı andan itibaren arayüz etkileşimlerini harekete geçirerek topluluk içerisinde tartışma ve katılım süreçlerini halihazırda başlatmış olmaktadır (Jenkins vd., 2016, s. 22). Örneğin, pusuda bekleyenler (lurkers) olarak bilinen pasif kullanıcılar, yorumları okuyan ancak mesaj yazmayan ya da yorum göndermeyen kullanıcılardır (Khan, 2017, s. 237). YouTube'daki viral fenomen videolar da güçlü birer örnek olarak karşımızda durmaktadır. Bu videolar kısa süre içinde e-posta ya da sosyal medya platformlarından hızla yayılarak popüler hale gelebilmektedir. Viral videolar binlerce yorum, beğenme ve beğenmeme gibi pratiklerle katılımcıları platforma çekmeye çalışmakta ve bunu başarmaktadır (Khan, 2017, s. 237).

YouTube'da veri akışını etkileyen bir diğer faktör profesyoneller tarafından oluşturulan içeriklerdir. Geçmişi reality ve talk şovlar, yarışmalar ve tartışma programlarına uzanan üretimleriyle medya holdingleri de video akış sisteminden yararlanmaya başlamıştır. Büyük medya şirketleri, YouTube'a giriş yapmaya başladıklarında ürettikleri profesyonel içerikler platformda, baskın format haline gelmeye başlamıştır (Kim, 2012, s. 58). Bu format değişikliği daha ziyadesiyle eski medyanın yeni teknolojilerle statü ve işlevleri değişmiş olarak varlığını sürdürmeye çalışmasıyla ilişkilidir (Jenkins, 2018, s. 31). Van Dijck (2009) platformda profesyonel içeriklerin (PGC videoları) çoğalmasıyla finansal bağımsızlık ve yaratıcı özerklik temelinde gelişen amatör ve gönüllü içeriklerin (UGC videoları) güçlenmesinin beklenemeyeceğini vurgulamaktadır.

YouTube'da katılım kültürünün gelişmesinde video kaydetme (cep telefonları, web kameraları veya dijital fotoğraf makinesi kameraları) yollarının çoğalmış olmasının öneminden bahseden Eggo Müller (2009) profesyonellerin ürettiği içeriklerle amatör kullanıcıların ürettiği içerikler arasındaki sınırların ortadan kalkmış olduğunu ifade etmektedir. Görülmektedir ki teknik olarak medyaya katılım kolaylaşsa da profesyonel içerikler (PGC videoları) çevrimiçi video kültürü içinde üretim ve tüketim alanındaki ilişkiyi yeniden tanımlamakta ve kurumsallaştırmaktadır. Profesyonel ve amatör video formatları arasında tanımlanan yeni sınırlar özellikle "kalite söyleminde" kendini belli etmektedir. Müller'e (2009) göre, YouTube'daki kaliteli söylemi, olası görsel-işitsel katılımcı eylemlerini sözleşmelere ve standartlara göre yapılandırmaya çalışmaktadır. Örneğin, YouTube kullanıcıları, platformun içerik (video) üretimi için istediği yönergeleri takip ederek ve uygulamaya çalışarak geleneksel medya estetiğine yaklaşır. Bu yönergeler ve rehberler Müller (2009) için YouTube'daki amatör içerik üreticilerini profesyonelleştirmek, "sıradan kullanıcıların" özgün yaratıcılıklarını evcilleştirmek anlamına gelmektedir. Örneğin, profesyonelliğe ulaşmak için en az bir kamerayı nasıl kullanacağını bilmek, kurgu (editing) yazııımı ile çalışmak, sıkışırma tekniklerini anlamak ve bu konularda istekli olup yetenekli hale gelmek içinse kişisel ekipmanlara, ayrıca belirli bir zaman ve kültürel sermayeye sahip olmak gerekmektedir (Lange, 2008, s. 90). Aşağıda, katılım kültürünün tartışma ve reklam modelleriyle şekillenen doğasından bahsedilecek ve kullanııının bu faktörler karşısındaki yeni konumu tartışılacaktır. 


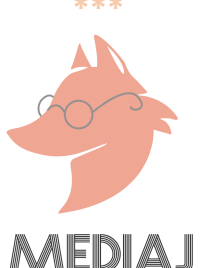

\section{YouTube'da Yorum ve Reklamlar}

Hesaplama ilkeleri ve yayılım hızı uyarınca van Dijck, katılımcı kavramını şirketlerin yönlendirdiği "aktif katııımcı" söylemi bağlamında sorgulamaktadır. Yazar, aktif katılımcının kim olduğunu ve ne tür içerikler üreten yeni medya kullanıcısının kullanıcı fail (user agency)'i ortaya çıkardığını tartışmaktadır. Van Dijck (2009) YouTube'daki aktif üreticinin 1980'lerden sonra "prosumer" (üre-tüketici) kavramıyla tartışıldığını bunun da profesyonel içerik üreticisi ve tüketici olmak üzere kullanıcıyı yalnızca iki kutba indirgendiğini belirtmektedir. Van Dijck'e (2009) göre, kullanıcı fail, bu iki kutuplu ayrımdan çok daha karmaşık olup kullanıcı ticaret, içerik ve bilgi arasındaki sınırların yeniden çizildiği bir medya ortamında çeşitlenen rolleriyle birlikte tartışılmalıdır. Örneğin, YouTube, Google tarafından satın alındıktan sonra kullanıcıların veri sağlayıcı rolleri anonim kullanım, çerezler, IP adresleri ve tıklama gibi akış verileri dolayımıyla artmakta, böylece kullanıcı katkılı içerik üretimi (user generated content) tüketici davranışına odaklanır hale gelmektedir (van Dijck, 2009, s. 48-50). Tüketici davranış seyrinin görülebileceği yerlerden biri tüketici yorumları olurken ikincisi, video trafiğindeki reklamlardır.

Her videonun altında gösterilen YouTube yorum özelliği, kullanıcılar arası etkileşimi ve tartışma ortamlarını teşvik etmekte ve veri tabanının ayrılmaz bir parçasını oluşturmaktadır (Khan, 2017, s. 236; Kessler \& Schafer, 2009, s. 284). YouTube, genişleyen bir katılımla şekillenen topluluk retoriğine rağmen daha ziyadesiyle beğeni ve içerik üretimi gibi bireysel katılımları daha çok teşvik etmektedir (Burgess \& Green, 2009, s. 67). Örneğin, platformda, videolara yapılan yorumlar videonun popülerliğini beslemekte ve meta bilgi üretmektedir (Kessler \& Schafer, 2009 , s. 284). Video altına yapılan yorumlar vasıtasıyla videolara yanıt üretilirken ortaya çıkan tepkiler ve bu tepkilerden doğan yeni tartışma konuları ile kullanıcılar birbirleriyle etkileşime girerler (Uricchio, 2009, s. 34). Platforma yüklenen videolara sadece yazılı olarak değil videolu yanıt göndererek de tartışma başlatılabilmektedir. Bu eylem izleyiciyi farklı aboneliklere yönlendirmek gibi bir amacı da içinde taşımaktadır. Örneğin, bazı durumlarda, videoya yapılan bir yorum ilgisiz bir konuya verilen bir tepkiden doğmakta, konu tartışılmakta ve farklı kanallara abonelikler bu sayede çoğalmaktadır (Kessler \& Schafer, 2009, s. 282-284). Videoları yanıtlamak, yorumlamak, beğenmek gibi geri bildirimler kullanıcılar arasında etkileşimleri başlattığı için Chau'ya (2010) göre, bu durum içerik oluşturucuları daha fazla videoyu dolaşıma sokmaya ve video oluşturmaya motive etmektedir. Örneğin, sürekli olarak "hayranlarını" okuyan ve onlara yanıt üreten YouTuber'ların abonelerini ellerinde tutma ve daha fazla görüntülenme elde etme olasılıkları diğer kullanıcılara göre daha yüksektir.

Videoları beğenme ve yorum yapma özelliğinin gençler arasında oldukça popüler olduğunu dile getiren Chau (2010) video yorum ve yanıtlarının kendini yeniden üreten döngüsel bir süreç yarattığını ifade etmektedir. Örneğin, YouTube'da bir iletişim türü olan Vlog'lar (video-blog), yorum bölümünde eleştiri ve tartışmaya zemin hazırlarken burada konular, siyasi tartışmalardan gündelik hayatın sıradan ayrıntılarına kadar uzanan bir çeşitlilik içindedir (Burgess \& Green, 2009a, s. 94). Vlog, izleyiciye doğrudan hitap etmenin doğası gereği geri bildirime davet eden bir form olduğundan videolara yanıt ve eleştiriler dinamik birer kültürel ortama kapı açmaktadırlar (Burgess \& Green, 2009a, s. 95). Jenkins (2013) yorum özelliği ile oluşan kültürel alanın, düşünceleri ifade etme ve öğrenme ortamı yaratmasının yanında acımasız ve kaba yorumların da sahiplenildiği bir yer olduğunu belirtmektedir. Lange (2008) ise videolara gelen homofobik, 


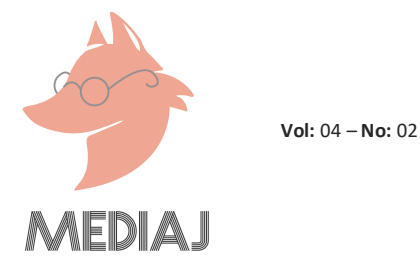

ırkçı, cinsiyetçi ve ölüm tehdidi gibi yorumların ve geri bildirimlerin miktarına ilişkin endişelerini dile getirmekte bu yorumlara karşı çıkmak için platform üzerinden bazı taktikler önermektedir. Bunlar arasında anlamsız yanıtları görmezden gelmek, incitici yanıtları silmek, saldırgan yorumları engellemek ya da YouTube personeliyle iletişime geçmek öneriler vardır. YouTube arayüzünün rahatsız edici içerik ve yorumlara karşı aldığı önlemlerden bir diğeri kullanıcı yorum türü olarak görülebilecek video işaretleme (video flagging) butonudur. Video işaretleme, kullanıcılara YouTube sosyal medya platformundaki herhangi bir videoya tepki vermeleri, videolara yanıt üretmeleri için sunulan hizmetlerden biridir (Kampman, 2008, s. 154). Fakat, YouTube politikaları, kullanıııları kendi politikaları konusunda bilgilendirip hizmet şartları ile ilgili onay mekanizmalarını devreye sokmasına rağmen kullanııların bu politikaların oluşumunu fikirsel olarak etkileyebilecekleri herhangi mekanizma bulunmamaktadır. YouTube'un, bir kullanııının şartlarını ne zaman ihlal ettiğini belirleme, videoları kaldırma ve hesapları feshetme konusunda yegâne takdir yetkisine sahip olduğu görülmektedir (YouTube, 2020; Stein, 2013, s. 363).

YouTube şirketi, yapılan yorumlardaki işaretlemeleri inceleyerek topluluk kurallarını ve yönergeyi ihlal eden videoları kaldırabilmektedir. İşaretlenen içeriklerin kapsamı ise oldukça geniştir: spam ve aldatıcı uygulamalar (sahte kimliğe bürünme), hassas içerikler (çocuk güvenliği, çıplaklık, cinsel içerik, intihar ve kendine zarar verme), şiddet barındıran içerikler (taciz, siber zorbalık, nefret söylemi, şiddet içeren suç görüntüleri), yasal düzenlemelere tabi ürünler (ateşli silahlar içeren içerik, yasadışı veya yasal düzenlemelere tabi malların satışı) (YouTube, 2020). ${ }^{5} \mathrm{Bu}$ topluluk kurallarına rağmen birçok kullanıcı, YouTube topluluk kurallarını ihlal eden yorumlar yapmaya devam etmektedir (Wotanis \& McMillan, 2014, s. 914). Lindsey Wotanis ve Laurie McMillan'a (2014) göre bu tarz yorumların bir diğer nedeni de topluluk kurallarına rağmen YouTuber ya da Vlogger'ların yapılan yorumlarla popülaritesi arttığı için bu yorumlar silinmeden bırakılır. Öte yandan Lange (2007) bazı genç içerik üreticilerinin çevrimiçi ifade özgürlüğünü desteklemek için kasıtlı olarak incitici yorumları kaldırmayı reddettiklerini aktarmaktadır. Kullanıcılar, videoya yapılan yorumları spam olarak işaretleyebilse de diğer topluluk ihlallerini tek tek ele almak yine de kanal sahiplerine düşmektedir. Platform kullanıcıları bir video yayınlarken yorumları devredışı bırakabilir, ekranda görüntüleyebilir ya da videolara yapılan yorumları silebilirler (Wotanis \& McMillan, 2014, s. 914). Örneğin, iklim adaleti konusunda bir aktivist ağı olan Never Trust a COP (NTAC), Iklim Değişikliği Sözleşmesi 15. Taraflar Konferansı (COP15 BM) öncesi tartışmaları alevlendirmek için YouTube'un sağladığı çevrimiçi mobilizasyonu kullanarak videolar yayınlamıştır. İklim konferansının gündeme getirdiği konular, YouTube aracılığıyla kullanıcı yorumları üzerinden tartışıımakta ve bu tartışmalar sonucunda çevrimiçi siyasal bir söylem ortaya çıkmaktadır. Diğer yandan bu aktivist sivil ağ, yorum yaparak tartışmaya katılma pratiklerinin düşmanlıkla karakterize edildiğini ve diyaloğa davet etmediğini belirterek bu yorumların sivil kültürlerin ortaya çıkışını engellediğini savunurlar (Uldam \& Askanius, 2013, s. 1185-1200). Ayrıca, aktivist videolarla ana akımdaki ticari videolar ve komedi gruplarının hazırladığı videoları birbirinden ayırmak giderek zorlaştığı için kültürel tartışma ortamının sınırları videolara yapılan yorumlar dahilinde giderek bulanıklaşmaktadır (Jenkins, 2018, s. 407).

Videolara yapılan yorumlar kadar videoların reklam çekme kabiliyetiyle katılımcılar arasındaki

\footnotetext{
${ }^{5}$ Ayrıntılı bilgi için bkz. https://www.youtube.com/howyoutubeworks/policies/community-guidelines/\#communityguidelines (Erişim Tarihi: 10 Aralık 2020)
} 


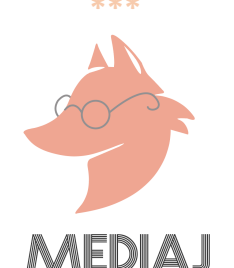

yarış da artmaktadır. Google öncesi dönemde YouTube, kullanıcılarını reklama yönlendirmezken platform satın alındıktan sonra YouTube'un reklam çekme potansiyeli hızla geliştirilmiştir (Wasko \& Erickson, 2009, s. 373-375). ilk olarak reklamsız ve amatör videolardan profesyonel videolara doğru bir geçiş yaşanmıştır (Kim, 2012, s. 57). Jane Arthurs ve Sophia Drakopoulou'a (2018) göre, YouTube, kullanıcı tarafından oluşturulan içerik üretiminin verimli bir şekilde para kazanma yollarına aktarıldığı önemli bir örneği temsil etmektedir. Bu yollardan biri de hiç kuşkusuz ki reklamcılıktır. Platform, kullanıcıların katılımına dayalı yeni para kazanma biçimlerini daha kolay hale getiren bir reklamcılık modelinin geliştirilmesinde özel bir rol üstlenmiştir. Platformun gittikçe artan popülaritesiyle sektörler platform üzerinden gelir elde etmeye oldukça ilgi göstermişlerdir. Video akışı sırasında oynatılan reklamların geliri, videoların görüntülenme sayısına bağlı olarak servis sağlayıcı (YouTube) ve içerik sağlayıcılar (telif hakkı sahipleri) arasında paylaştırılmaktadır (Kim, 2012, s. 57). Reklam şirketlerinin kullanıc verilerini elde edebilmesi için öncelikle YouTube Gizlilik Sözleşmesi, kişisel bilgilerin toplanması ve kullanılması hususunda kullanıcıyı bilgilendirmektedir. Şirket, bu sosyal medya platformuna gönüllü olarak yüklenen her türlü kullanım bilgisini doğrudan ve dolaylı olarak toplama yetkisine sahip olmaktadır (YouTube, 2020). Bu bilgiler, hizmetleri özelleştirmek, kullanıcı etkinliklerini ve iletişimini izlemek, hedeflenen pazarlamayı etkinleştirmek gibi amaçlarla şirket tarafından kullanılmaktadır (Stein, 2013, s. 362). Kullanıcı verilerine ulaşarak gelir elde etme dışında YouTube, ana sayfasında gösterilen sponsorlu videolardan (promoted videos) ve anahtar kelimelerin satışından da gelir elde eder. Bu anahtar kelimeler en yüksek fiyat teklifi veren reklam verene satılmakta ve böylece reklam verenin videoları, kullanıcının arama sonuçlarında sıralanmaktadır (Kim, 2012, s. 57-58). Reklam geliri YouTube'da, TV endüstrisinden Web ortamlarına doğru bir pazar genişlemesiyle birlikte yol alır. Çevrimiçi video hizmeti popüler hale geldikçe medya endüstrileri, video akış hizmetinin yeniden iletim kanalları ve etkileşim tabanlı reklam özelliklerini fark etmeye başlamıştır (Kim, 2012, s. 58-61). Örneğin, YouTube'da kullanıcılar ana akım medyadan belli formatları alarak videolarını oluşturduklarından eski ve yeni medya ortamları için video paylaşım platformları giderek bir tanıtım aracı olarak işlev görmeye başlamıştır (Kim, 2012, s. 65).

Internetin reklam verenler için çekici yönü, bir şirketin reklam yatırımının etkinliğini hassas bir şekilde ölçme becerisidir (Farchy, 2009, s. 363). YouTube'daki kullanıcıların veri sağlayıcı rollerinin anonim kullanım verileri, çerezler, IP adresleri ve tıklama akış verileriyle izlenmekte olduğu belirtilmiştir (van Dijck, 2009, s. 48). Bu veri akış ekonomisinde elde edilen meta bilginin dışında önemli olan bir diğer unsur, ziyaretçi trafiğinin kontrolüdür. Platform, Web 2.0 sağlayıcıları ile reklam verenler arasındaki "aracı" rolüyle iki şirket arasında iş birliği sağlamakta, izleyici parasallaşırken ücretsiz video akış hizmeti bu yolla izleyiciye ulaşmaktadır (Farchy, 2009, s. 362-367). Ticari içeriğin iletimi için YouTube gibi etkileşimli bir platformun avantajlarından bir diğeri, kullanıcı davranış kalıpları ve yanıtları hakkında giderek daha ayrıntılı bilgilerin yakalanmasıdır. Etkileşimli pazarlamacılar kullanıcıları geçmişleri, zevkleri ve davranışları hakkında genişleyen bir bilgi yelpazesine dayalı olarak hedef kitlelerine ayırmaktadır. Ayrıca platformlar aracılığıyla tüketici ve izleyici davranışlarını yönetme ve bu davranışları belirli bir yere kanalize etmek için de onları teşvik etmektedir (Andrejevic, 2009, s. 415). Bu niş pazarlama potansiyeli İnternetle birlikte daha da artmış gelişmiş dijital teknolojiler bireysel sosyal davranışın izlenmesini kolaylaştırmıştır. İçerik üreticileri, reklamcılar ve tüketiciler arasında zaten yakın olan ilişki daha da samimi hale gelmiştir (van Dijck, 2009, s. 47). Kullanıcı verileri hedefli reklamcılık için kullanılırken kullanııının ise bu veriler üzerinde herhangi bir gücünün 


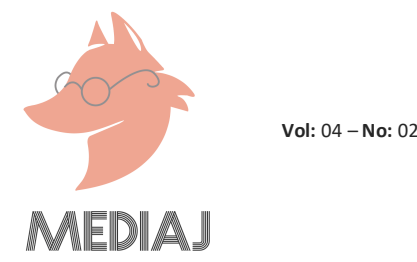

bulunmadığı görülmektedir. Bu meta verileri kullanma izni genellikle kullanıcıların imzalaması gereken bir hizmet sözleşmesine dayanmaktadır (van Dijck, 2009, s. 47). Örneğin, YouTube Ortaklık Programı (YouTube Partnership Program) platformun tanınmış katılımcılarına sağlanan reklam geliri için ayrıcalık tahsis ederek katılımcının reklam geliri ayrıcalıklarıyla statüsünü yükseltmektedir (Chau, 2010, s. 67). Girişimci Vlogger ve YouTuber'lar, YouTube'un reklam paylaşım planına katılırlar ve platformdaki varlıklarından gelir elde ederler (Burgess \& Green, 2009a, s. 103). Böylece, "dikkat sermayesi" olarak adlandırılan reklam yoluyla platformdan para kazanan YouTube şöhretleri için ticari bir kaynak yaratılmış olmaktadır (Smith, 2017, s. 3). Kullanıcıların reklam gelirleri elde etmek için kanala abone çekme mücadeleleri van Dijck'e (2009) göre, kullanıc katkılı içerikleri dağıtan platformları ticari olarak yönlendirilen platformlara dönüştürmektedir. Reklamların içeriklere bir diğer etkisi ise Jin Kim'e (2012) göre, reklam alan "kaliteli" profesyonel içeriğe sahip videoların bir damga görevi üstlenmesidir. İzleyiciler reklam almayan amatör içerikleri izlemeye değer bulmamakta Kim'e (2012) göre, kullanıcı katkılı içeriklerin (UGC) profesyonel içerikler (PGC) tarafından marjinalleştirilme ihtimali geçerliliğini arttırmaktadır. YouTube'un reklam gelirlerini yönetme ve medya şirketleriyle olan iş birliği sayesinde kullanıcılar, videolarına reklam alabilmek ve daha fazla abone kazanabilmek için YouTube arayüz tasarımına uygun ve "kaliteli" içerikler üretmeye yönelmektedirler. Böylelikle katılımcı kültürel olanaklar açısından YouTube sosyal medya platformunun amatör içerik üretimleri git gide daha dar bir kültürel alana doğru sıkıştırılmaktadır.

\section{SONUÇ VE DEĞERLENDIRME}

İzleyici ve katılımcı olgularının net bir ayrım kategorisi oluşturamadığı dijital kültürde medya endüstrisine yön veren temel dinamiğin "kullanıcı" olduğu görülmektedir. Ev videolarında, özel günleri kaydetme ve kaydedilen videoları tekrar izlemeye dayalı bir video izleme deneyiminden gündelik hayatın her anının kaydedilip izleyicinin beğeni beklediği bir edim değişikliğine giden yolda izleyici deneyimi ben ve öteki, zaman ve mekân boyutlarıyla yeniden yorumlanmaktadır. İzleyicinin video izleme deneyimini köklü bir şekilde dönüştüren bir video arşiv platformu olan YouTube, Google tarafından satın alındıktan sonra platformun kolektif iş birliğine ve gönüllüğe dayanan ilkeleri, şirket politikalarıyla tekrar yapılandırılmıştır. Bu yapılandırma izleyiciyi kullanıcı olarak giderek artan bir oranda sorumluluk almaya "zorlamıştır". Bu sosyal medya platformu, izleyiciden kullanıcı olarak aktif içerik üretimi beklemekte, kullanıcı da şirket kurallarını değiştirebileceğine dair bir beklenti içine girmektedir. YouTube'un içerik üreticisi için sürekli geliştirdiği rehberler, talimat ve yönergeler katılımcı kültürle gelişen altkültür grupların yaratıcılıklarını şirket politikalarının bireysel politikalarına eklemlemektedir.

İzleyici trafiğinin kontrolü YouTube'un bugün geldiği noktada şirket kârını etkileyen başlıca etmenlerden biridir. YouTube kanalına üye olunduğu andan itibaren bu sosyal medya platformunda veri akışı başlamaktadır. İçerik üretmeyen izleyici hiçbir tartışmaya katılmasa beğenide bulunmasa dahi yalnızca tek bir tıklama işlemi veri akışını başlatmaya yetmektedir. İzleyiciler, bir videoya yöneldiklerinde YouTube algoritması bir öneri sistemiyle kişiyi en popüler ve en beğenilen videolara yönlendirmektedir. Bu durum izleyiciyi içerik çeşitliliği oldukça bol bir havuza yönlendirmiş gibi gözükse de bu istatistiki sıralama, görüntülenme sayısına bağlı içerikler arası bir kısırdöngü yaratmaktadır. İçerik üreticileri açısından da videolarının üst sıralara çıkması için yanlış başlığa bilerek yönlendirme gibi taktiklerin çoğalmasına neden olmaktadır. Ayrıca 


\section{MEIDIAJ}

reklam alan, çok beğenilen ve çok tartışılan profesyonel içerikleri az beğeni alan amatör içeriklerin önüne taşıyan algoritma, katılımcı kültürü besleyen yaratıcı içerikleri bir "sıralama kültürüne" dönüştürmektedir. YouTube'a ilişkin yapılan eleştirel literatür değerlendirmesinde kullanıcıların veriler üzerinde herhangi bir söz hakkının bulunmadığı, katııımcı kültürün aktörleri olan kullanıcıların platformun gizlilik sözleşmesini onaylamak ya da onaylamamaktan öteye gidemedikleri görülmektedir. Bu çalışma, YouTube'u kültürel, ekonomik ve teknolojik yönleriyle ilişkisel olarak ele almaya çabalamıştır. Bu sebeple çalışma, YouTube üzerinden katılımcı kültürel pratikleri ele almak isteyen araştırmacılar için çok yönlü bir perspektif sunmayı amaçlamaktadır.

\section{KAYNAKÇA}

Akbaş, Ö. U., Atalay, G. E. (2020). Geleneksel kadınlık rollerinin sosyal medyada yeniden üretimi: kendine yardım temalı YouTube kanallarına yönelik çok modlu eleştirel söylem analizi. Kültür ve Illetişim, 23(45), 58-86. https://doi.org/10.18691/kulturveiletisim.709724

Alp, Y., Kaleci, D. (2018). YouTube sitesindeki videoların eğitim materyali olarak kullanımına ilişkin öğrenci görüşleri. International Journal of Active Learning, 3(1), 57-68. https://dergipark.org.tr/tr/download/article-file/435887

Altun, Ş. (2019, Ekim 16). Sosyal medya ve şöhret kültürü: YouTube örneği. [Yüksek Lisans Tezi, İstanbul Gelişim Üniversitesi]. YÖK Ulusal Tez Merkezi.

Andrejevic, M. (2009). Exploiting YouTube: contradictions of user-generated labor. P. Snickars \& P. Vonderau (Ed.), The YouTube reader (ss. 406-424). Logotipas.

Arklan, Ü., Kartal, N. Z. (2018). Y kuşağının içerik tüketicisi olarak YouTube kullanımı: kullanım amaçları, kullanım düzeyleri ve takip edilen içerikler üzerine bir araştırma. Gümüşhane Üniversitesi Illetişim Fakültesi Elektronik Dergisi, 6(2), 929-965. https://doi.org/10.19145/egifder.443959

Arthurs, J., Drakopoulou, S., Gandini, A. (2018). Researching YouTube. Convergence: The International Journal of Research Into New Media Technologies, 24(1), 3-15. https://doi.org/10.1177/1354856517737222

Ata, A., Atik, A. (2016). Alternatif bir eğitim-öğretim ortamı olarak video paylaşım siteleri: üniversitelerdeki YouTube uygulamaları. Social Sciences, 11(4), 312-325. https://dergipark.org.tr/tr/pub/nwsasocial/issue/24580/260212

Atalay, G. E. (2019). Sosyal medya ve çocuk: "Babishko Family Fun TV" isimli Youtube kanalının eleştirel bir analizi. Erciyes iletişim Dergisi (1), 179-202. https://doi.org/10.17680/erciyesiletisim. 484856

Ateşalp, S., Başlar, G. (2015). Katılımcı kültür tartışmaları ekseninde sosyal medyada diziler: Kardeş Payı örneği. Intermedia International E-journal, 2(1), 158-180. https://dergipark.org.tr/tr/pub/intermedia/issue/8644/107919 


\section{MEDIAJ}

Aydoğdu, A. G., Illhan, E. (2020). Alternatif bir iletişim aracı olarak YouTube: 2019 yerel seçimlerinde sokak röportajları yapan siteler üzerine bir inceleme. Selçuk Üniversitesi Sosyal Bilimler Meslek Yüksekokulu Dergisi, 23(2), 433-442. https://doi.org/10.29249/selcuksbmyd.688536

Biçer, S., Şener, Y. (2020). Kullanımlar ve doyumlar yaklaşımı bağlamında üniversite öğrencilerinin Youtube kullanım alışkanlıkları. Selçuk iletişim, 13(2), 589-627. https://dergipark.org.tr/tr/pub/josc/issue/55089/697809

Binark, M., Löker, K. (2011). Sivil toplum örgütleri için bilişsim rehberi. STMG.

Bulut, S. (2020). Egemen söylemin kıyısındakiler: alternatif bir platform olarak Youtube'da gazetecilik ve gazeteciler üzerine bir inceleme. Erciyes iletişim Dergisi, 7(2), 727-748. https://doi.org/10.17680/erciyesiletisim.684979

Burgess, J., \& Green, J. (2009). YouTube: online video and participatory culture. Polity Press.

Burgess, J., \& Green, J. (2009a). The entrepreneurial vlogger: participatory culture beyond the professional-amateur divide. P. Snickars \& P. Vonderau (Ed.), The YouTube reader (s. 89108). Logotipas.

Carpentier, N. (2011). Media and participation. Intellect.

Chau, C. (2010). YouTube as a participatory culture. New Directions for Youth Development (128), 65-74. https://doi.org/10.1002/yd.376

Clement, J. (2020). YouTube-statistics\&facts. Statista. https://www.statista.com/topics/2019/youtube/

Çelik, Y. G. (2018, Nisan). YouTube sosyal paylaşım ağının popüler müzik üzerine etkisi: 2010 yılı sonrası dönemde Türkiye örnekleri incelemesi. [Yüksek Lisans Tezi, İstanbul Kültür Üniversitesi]. YÖK Ulusal Tez Merkezi.

Çetin, Ş. E. \& Ayhan, A. (2020). Katılımcı kültür olgusu bağlamında sosyal medya: netnografik bir analiz. Intermedia International E-journal, 7(12), 47-69. https://dergipark.org.tr/tr/pub/intermedia/issue/55160/721727

Deuze, M. (2006). Participation, remediation, bricolage: considering principal components of a digital culture. The Information Society, 22(2), 63-75. https://doi.org/10.1080/01972240600567170

Dijck, J. van (2009). Users like you? Theorizing agency in user-generated content. Media, Culture \& Society, 31(1), 41-58. https://doi.org/10.1177/0163443708098245

Duncum, P. (2011). Youth on YouTube: prosumers in a peer-to-peer participatory culture. The International Journal of Art Education, 9(2), 24-39. 


\section{MEDIAJ}

https://ed.arte.gov.tw/uploadfile/periodical/3052_9-2-p.24-39.pdf

Erdoğan, ì. (2020). Yeni medya aptallığı: Youtube videolarında aptalca şeyler yapmanın ve söylemenin ekonomi politiği. TRT Akademi, 6(10), 742-765. https://dergipark.org.tr/tr/pub/trta/issue/56639/699139

Ergen, Y. (2019). Popüler kültürün popüler rol modelleri youtuberlar: ilköğretim çağındaki özel okul öğrencileri üzerine bir araştırma insan ve Toplum, 9(1), 117-154. https://doi.org/10.12658/M0284

Fagerjord, A. (2010). After convergence: YouTube and remix culture. J. Hunsinger, L. Klastrup \& M. Allen (Ed.), International Handbook of Internet Research (ss. 187-201). Springer.

Farchy, J. (2009). Economics of sharing platforms: what's wrong with cultural industries? P. Snickars \& P. Vonderau (Ed.), The YouTube Reader (ss. 360-372). Logotipas. NotaBene.

Fuchs, C. (2020). Sosyal medya: eleştirel bir giriş (D. Saraçoğlu ve i. Kalaycı, Çev.).

Gelebek, E. (2020, Şubat). Gündelik kültür oluşturmada yeni medya araçlarının rolü: Youtube örneği. [Yüksek Lisans Tezi, Maltepe Üniversitesi]. YÖK Ulusal Tez Merkezi.

Genç, M. (2019, Ekim 7). Kadınlararası bir güçlenme alanı olarak güzellik: Youtube güzellik kanalları örneği. [Doktora Tezi, Hacettepe Üniversitesi]. YÖK Ulusal Tez Merkezi.

Güler, M. (2018). Dijitalleşen kapitalizmin yeni aktörleri: youtuberlar. Intermedia $\begin{array}{lll}\text { International } \quad \text { E-journal, } & \text { 5(9), }\end{array}$ https://dergipark.org.tr/tr/pub/intermedia/issue/42605/513496

Gülüm, E. (2019). Geleneksel kültür, medya müzeciliği ve Youtube. Folklor/Edebiyat, 25(99), 491-500. https://doi.org/10.22559/folklor.895

Gülüm, E. (2020). Alevi-Bektaşi inanç belleğinin sosyal medyayla imtihanı: Youtube'daki semah kayıtları. Motif Akademi Halkbilimleri Dergisi, 13(32), 1390-1405. https://doi.org/10.12981/mahder.821509

Güzel, B. B., Çakır, H. \& Çelen, Y. (2020). Youtube üzerinden video destekli keman öğretimine ilişkin öğrenci görüşleri. Bilim Eğitim Sanat ve Teknoloji Dergisi, 4(1), 31-43. https://dergipark.org.tr/tr/pub/bestdergi/issue/50074/626503

Hall, S. \& Jefferson, T. (1993). Resistance through rituals: youth subcultures in post-war Britain. Routledge.

Hebdige, D. (2004). Altkültür: tarzın anlamı (S. Nişancı, Çev.). Babil Yayınları.

Hootsuite. (2020). Digital 2020: global digital yearbook. Wearesocial. https://wearesocial.com/digital-2020 


\section{MEDIIAJ}

İlhan, E. \& Aydoğdu, A. G. (2018). Türkiye'de YouTube yayıncılığı ve youtuber olmak. Journal of Communication Theory \& Research/Iletisim Kuram ve Arastirma Dergisi (47), 141-166. https://app.trdizin.gov.tr/makale/TXpJNE9EUXINZz09/turkiye-de-youtube-yayinciligi-veyoutuber-olmak

İlhan, E. \& Aydoğdu, A. G. (2019). Youtube kullanıcılarının kullanım motivasyonlarının incelenmesi. Gümüşhane Üniversitesi Iletişim Fakültesi Elektronik Dergisi, 7(2), 1130-1153. https://dergipark.org.tr/en/pub/e-gifder/article/570677

Işıkman, N. G. (2016). Genç Lumiere'lerin yeni mecrası Youtube. Atatürk Iletişim Dergisi (10), 5-18. https://dergipark.org.tr/tr/pub/atauniiletisim/issue/33795/374263

Iversen, G. (2009). An ocean of sound and image: Youtube in the context of supermodernity. P. Snickars \& P. Vonderau (Ed.), The YouTube reader (ss. 347-358). Logotipas

Jenkins, H. (2006). Convergence culture. New York University Press.

Jenkins, H. (2018). Cesur yeni medya: teknolojiler ve hayran kültürü (N. Yeğengil, Çev.). Iletişim Yayınları.

Jenkins, H. \& Carpentier, N. (2013). Theorizing participatory intensities: A conversation about participation and politics. Convergence: The International Journal of Research into New Media Technologies, 19(3), 265-286. https://doi.org/10.1177/1354856513482090

Jenkins, H., Ito, M. \& Boyd, D. (2016). Participatory culture in a networked era. Polity Press.

Kampman, M. (2008). Flagging or fagging: (self-)censorship of gay content on YouTube. G. Lovink \& S. Niederer (Ed.), Video vortex reader: responses to YouTube (ss. 153-161). Institute of Network Cultures.

Kavoori, A. (2015). Making sense of YouTube. Global Media Journal, 13(24), 1-25. https://www.globalmediajournal.com/open-access/making-sense-of-youtube.php?aid=54890

Kessler, F., \& Schäfer, M. T. (2009). Navigating YouTube: constituting a hybrid information management system. P. Snickars \& P. Vonderau (Ed.), The YouTube reader (ss. 275-292). Logotipas.

Khan, M. L. (2017). Social media engagement: what motivates user participation and consumption on YouTube? Computers in human behavior, (66), 236-247. https://doi.org/10.1016/j.chb.2016.09.024

Kim, J. (2012). The institutionalization of YouTube: from user-generated content to professionally generated content. Media, culture \& society, 34(1), 53-67. https://doi.org/10.1177/0163443711427199

Kuyucu, M. (2019). Y kuşağı ve youtube: y kuşağının youtube platformunu kullanım amaçları. Journal of International Social Research, 12(63). 
Lange, P. (2008). (Mis)Conceptions about YouTube. G. Lovink \& S. Niederer (Ed.), Video vortex reader: responses to YouTube (ss. 87-101). Institute of Network Cultures.

Lange, P. G. (2007). Publicly private and privately public: Social networking on YouTube. Journal of computer-mediated communication, 13(1), 361-380. https://doi.org/10.1111/j.10836101.2007.00400.x

Manovich, L. (2008). The practice of everyday (media) life. G. Lovink \& S. Niederer (Ed.), Video vortex reader: responses to YouTube (ss. 33-45). Institute of Network Cultures.

Müller, E. (2009). Where quality matters: discourses on the art of making a YouTube video. P. Snickars \& P. Vonderau (Ed.), The YouTube reader (ss. 126-140). Logotipas.

Neuman, W. L. (2010). Toplumsal araştırma yöntemleri: nitel ve nicelik yaklaşımlar. (S. Özge, Çev). Yayın Odası Yayınları.

News, BBC. (2020). Türkiye'de sosyal medya ne kadar ve nasıl kullanılıyor? BBC. https://www.bbc.com/turkce/haberler-turkiye-53259275

Özüz, E. (2018, Haziran 4). Dijital sosyoloji perspektifinden toplumsal değerlerin değişme sürecinde youtuberlar: ilköğretim öğrencileri örneği. [Yüksek Lisans Tezi, Hacettepe Üniversitesi]. YÖK Ulusal Tez Merkezi. https://tez.yok.gov.tr/UlusalTezMerkezi/tezSorguSonucYeni.jsp

Pazarbaşı, Ç. K., \& Toğlukdemir, M. (2019). Türkiye'deki gençlerin video paylaşım ve canlı yayın platformları deneyimlerinin etnografik araştırma metotlarından yararlanarak incelenmesi. Sanat Dergisi (34), 114-131. https://dergipark.org.tr/tr/pub/ataunigsfd/issue/49533/599427

Peters, K. \& Seier, A. (2009). Home dance: mediacy and aesthetics of the self on Youtube. P. Snickars \& P. Vonderau (Ed.), The YouTube reader (ss. 187-204). Logotipas.

Rieder, B., Matamoros-Fernández, A. \& Coromina, Ò. (2018). From ranking algorithms to 'ranking cultures' investigating the modulation of visibility in YouTube search results. Convergence: The International Journal of Research into New Media Technologies, 24(1), 50-68. https://doi.org/10.1177/1354856517736982

Schröter, J. (2009). On the logic of the digital archive. P. Snickars \& P. Vonderau (Ed.), The YouTube reader (ss. 330-347). Logotipas.

Smith, D. R. (2017). The tragedy of self in digitised popular culture: the existential consequences of digital fame on YouTube. Qualitative Research, 17(6), 699-714. https://doi.org/10.1177/1468794117700709

Stein, L. (2013). Policy and participation on social media: the cases of YouTube, Facebook, and Wikipedia. Communication, Culture \& Critique, 6(3), 353-371. https://doi.org/10.1111/cccr.12026

Stiegler, B. (2009). The carnival of the new screen: from hegemony to isonomy. P. Snickars 


\section{MEDIAJ}

\& P. Vonderau (Ed.), The YouTube reader (ss. 40-60). Logotipas.

Strangelove, M. (2010). Watching YouTube: extraordinary videos by ordinary people. University of Toronto Press.

Uldam, J., \& Askanius, T. (2013). Online civic cultures? debating climate change activism on Youtube. International Journal of Communication, 7 (20), 1185-1204. https://ijoc.org/index.php/ijoc/article/view/1755/920

Uricchio, W. (2009). The future of a medium once known as television. P. Snickars \& P. Vonderau (Ed.), The YouTube reader (ss. 24-40). Logotipas.

Wasko, J., \& Erickson, M. (2009). The political economy of Youtube. P. Snickars \& P. Vonderau (Ed.), The YouTube reader (ss. 372-387). Logotipas.

Wotanis, L., \& McMillan, L. (2014). Performing gender on YouTube: how Jenna Marbles negotiates a hostile online environment. Feminist Media Studies, 14(6), 912-928. https://doi.org/10.1080/14680777.2014.882373

YouTube. (2020). Youtube. https://www.youtube.com/intl/tr/about/

YouTube. (2020). Community guidelines. Youtube. https://www.youtube.com/howyoutubeworks/policies/community-guidelines/\#enforcingpolicies

Zanatta, J. A. (2017, Mayıs). Understanding youtube culture and how it affects today's media. [Yüksek Lisans Tezi, Dominican University of California]. https://doi.org/10.33015/dominican.edu/2017.CMS.ST.03

Zinderen, i. E. (2020). Yeni medya ekolojisi ekseninde Youtube: Türkiye örneği. Atatürk Üniversitesi Sosyal Bilimler Enstitüsü Dergisi, 24(1), 215-232. https://dergipark.org.tr/tr/pub/ataunisosbil/issue/53123/677295 